\title{
Analysis of Existing Passenger Traffic by Mode of Transport and Assessment the Competitiveness High-Speed Traffic in Ukraine
}

\author{
Anna Shevchenko (i) 1 , Natalya Bugaec (ii) 2 , Nadiia Murygina (iil 3 , \\ Yevhen Korostelov (ii) ${ }^{4}$, Gintas Viselga \\ ${ }^{1,4}$ Department of Research and Design of Communications, Geodesy and Land Management, \\ Faculty of Building, Ukrainian State University of Railway Transport, Kharkiv, Ukraine \\ ${ }^{2,3}$ Department of Way and Track Facilities, Faculty of Building, \\ Ukrainian State University of Railway Transport, Kharkiv, Ukraine \\ ${ }^{5}$ Department of Mechanics and Materials Engineering, Faculty of Mechanics, \\ Vilnius Gediminas Technical University, Vilnius, Lithuania
}

Received 14 February 2020; accepted 21 April 2020

\begin{abstract}
The article analyses the volume of passenger traffic from 1990 to 2019 for land, water and air transport. From the materials obtained and the experience of the networks of European and world high-speed railways, goals are set. High-speed lines designed exclusively for passenger traffic. This moment plays an important role in reducing the cost of construction, increasing the market and economic profitability. According to the data from the State Statistics Service of Ukraine, it is possible to calculate the passenger flow based on the known parameters for 2020-2032 in the direction of Kiev-Lviv. The design of high-speed lines should meet general requirements aimed at satisfying the basic characteristics of a high-speed railway system, which works in conjunction with the European High-Speed Railway network. The compatibility of the parameters of high-speed lines with the parameters of traditional lines is part of the operational requirements for the gradual introduction of a network of high-speed railways. Possible scenarios to achieve the required compatibility should cover all subsystems.
\end{abstract}

Keywords: passengers, traffic, various modes of transport, high-speed railway system, high-speed lines, network of railways, network of highways, passenger flow analysis.

\section{Introduction}

Creating communication between cities, especially between large cities, which are economic, cultural and tourist centers, is a necessity for modern society, as people need to move from city to city.

To achieve this goal, it is necessary to create a network of railways and highways, including motorways and air transport systems. The creation of a system of high-speed railways is another development direction to ensure convenient communication between cities.

People always tend to drive as fast as possible. The history of mankind and the development of vehicles confirms this characteristic feature. Achieving the goal of creating a message between cities using any system will allow people to move from city to city. High-speed railway - a symbol of modern society - will provide a fast, safe, frequent, convenient and efficient way to get around, accessible to everyone. Wherever a high-speed railway is created, transporting people becomes a truly thriving type of service (Shevchenko et al., 2019).

\section{High speed rail tasks}

The existing railways in Ukraine are characterized by a very slow speed of transportation, usually a trip from city to city is carried out at night. Using high-speed railways that transport passengers at high speeds and with high frequency, trips will mainly be made in the daytime. The system of movement will change radically (Shevchenko et al., 2018).

Due to the significant reduction in train travel time, all existing high-speed railways have great commercial success. A new way to travel with a high-speed train radically changes the ground transportation system, revitalizes rail passenger transportation and remains very competitive with air transport at distances up to $1.500 \mathrm{~km}$ (Shevchenko, 2018).

*Corresponding author. E-mail: gintas.viselga@vgtu.lt 
High-speed rail does not harm the environment due to the following factors:

- The most efficient way to consume energy and minimize environmental pollution;

- The shortest lines;

- The area of occupied land is half the area occupied by highways with $2 \times 2$ lanes;

- Solving the problem of congestion on roads;

- Solution to reduce the saturation of airspace and airports.

High-speed rail is also the safest mode of transport. It has a significant positive impact on economic activity (trade, tourism, hotel business, various types of services, etc.), urban development, real estate, employment, image of the country, etc. (Fischer \& Nèmeth, 2018).

Thus, the high-speed railway takes an active part in the development of the country. In Ukraine, the number of cars in 2040 will reach 22.5 million, and the number of cars per 1000 people -448 . Such a density of cars will create many problems associated with congestion on roads in cities, as well as increase environmental pollution. The creation of a high-speed railway is necessary to solve the problems of long-distance travel in the future.

Based on the experience of the networks of European and world high-speed railways, the following goals can be distinguished:

- Lines designed exclusively for passenger traffic;

- Compatibility of the high-speed rail system with the existing railway network;

- Operation based on the principles of high frequency and competitive short travel times.

High-speed lines designed exclusively for passenger traffic. This moment plays an important role in reducing the cost of construction, increasing the market and economic profitability. The following are the benefits of this option:

- Significant reductions in the cost of infrastructure by creating steeper slopes, reducing the number and size of the necessary structures (tunnels, overpasses, etc.) and providing straight lines, thereby reducing the length of new lines that will be built, and reducing accordingly, travel time;

- Maximum utilization of the load of the new line by uniform distribution of the speed of high-speed trains on the new lines;

- The provision of a new line exclusively for passenger traffic. Due to this, the load on existing lines is significantly relieved and optimal operation is ensured in both cases, since the trains will travel at approximately the same speeds. This factor is especially important for Ukraine, since Ukrzaliznytsia has extremely large volumes of freight traffic.

By ensuring compatibility with the existing network, trains of high-speed trains will be able to move along existing routes and enter the city center, creating access to the network throughout its territory. This is achieved by the following:

- Penetration into the city center using existing lines, without the need to build additional ones, which would entail significant costs;

- No need to change trains at either end of the new line;

- The gradual introduction and expansion of high-speed rail services.

Such an approach will help to reduce the cost of constructing a new line, expand the potential coverage of the territory and increase traffic volumes. High-speed trains will be able to continue traveling on regular railway lines at speeds allowed by local lines. Thus, they will be able to serve cities located at a distance of several hundred kilometers from the new line (Connolly \& Forde, 2015).

For countries with problems with gauge, (the difference between the traditional gauge and the width required for high-speed trains), new lines can still be drawn to existing stations by modifying the existing gauge at the station sections. However, a solution aimed at a significant coverage of the territory may be the manufacture of rolling stock, which automatically changes the gauge, as is done in the Spanish AVE network using Talgo trains (Nikitin, 2018).

High Speed Compounds-these are light weight two-stroke formulations with high power ratings that can be paired. As a result, they are able to achieve commercial exploitation speeds of $300-350 \mathrm{~km} / \mathrm{h}$ and high average income in some regions at a speed of $250-300 \mathrm{~km} / \mathrm{h}$. Such a profitable speed significantly reduces the duration of trips, due to which the duration of trips at a distance of up to $1.500 \mathrm{~km}$ is absolutely competitive compared to air transportation. Pass quite often, despite the limited number of trains, due to fast turnaround (push-pull design and the ability to easily change direction at stations) and fast movement (Nikitin, 2018). Achieve full workload during periods of maximum passenger traffic on new lines by creating a longer train by connecting the two trains (Sysyn et al., 2018).

High-speed rail, based on the principle of a significant increase in the frequency of flights and a reduction in travel time, is a completely new way of moving people. An unexpected significant increase in traffic volumes can be explained by this phenomenon.

The indicated technical design options for high-speed railways have proven their reliability in France and in Europe. They made it possible:

- Achieving a high average commercial speed of $250-300 \mathrm{~km} / \mathrm{h}$;

- Optimization of the use of high-speed train trains and the commercial load of the new line; 
- Reduced operating and maintenance costs of the new line and rolling stock;

- Freedom for freight on existing conventional rail lines.

All these factors contributed to the growth of traffic volumes, increased profitability and increased return on investment in the project of high-speed railways (Kirpa, 2004).

Based on the tasks and basic principles of creating a network of high-speed railways from a study of the authors (Ugnenko et al., 2020) the routes connecting settlements with a population of more than 300 thousand inhabitants are described in detail and fully, and the duration of the trip is calculated at existing speeds and with the introduction of high-speed traffic. The network of high-speed railways proposed for Ukraine will be implemented over 30-40 years, with the possible launch of the first project in 2020 or 2025. In the study, the speed of $350 \mathrm{~km} / \mathrm{h}$ is taken as the base speed. The calculation of the duration of trips of high-speed rail and existing from Kiev, Kharkov, Odessa, Lviv and the Dnieper is presented (Sysyn et al., 2018).

\section{Analysis of traffic volume by various modes of transport}

The total passenger traffic in Ukraine is presented in Table 1 based on information from the State Statistics Service of Ukraine.

Table 1. The total passenger traffic in Ukraine from 1990 to the present

\begin{tabular}{|l|c|c|c|c|c|c|c|c|c|c|c|c|c|c|}
\hline \multirow{2}{*}{ Vehicle } & \multicolumn{7}{|c|}{ Millions of passengers } & \multicolumn{1}{c|}{$\%$} \\
\cline { 2 - 16 } & 1990 & 1995 & 2000 & 2005 & 2010 & 2015 & 2019 & 1990 & 1995 & 2000 & 2005 & 2010 & 2015 & 2019 \\
\hline $\begin{array}{l}\text { All ground } \\
\text { transportation }\end{array}$ & 14917 & 6802 & 7819 & 7905 & 8157 & 8416 & 8710 & 99,60 & 99,79 & 99,91 & 99,92 & 99,91 & 99,92 & 99,91 \\
\hline Railway & 669 & 577 & 499 & 487 & 501 & 498 & 513 & 4,47 & 8,47 & 6,38 & 6,16 & 6,14 & 5,91 & 5,88 \\
\hline $\begin{array}{l}\text { Motor } \\
\text { transport }\end{array}$ & 8331 & 3483 & 2604 & 2502 & 2714 & 2816 & 3159 & 55,63 & 51,10 & 33,27 & 31,63 & 33,24 & 33,43 & 36,24 \\
\hline Trams & 2007 & 822 & 1381 & 1457 & 1468 & 1454 & 1614 & 13,40 & 12,06 & 17,65 & 18,42 & 17,98 & 17,26 & 18,51 \\
\hline Trolleybuses & 3232 & 1359 & 2581 & 2735 & 2653 & 2735 & 2513 & 21,58 & 19,94 & 32,98 & 34,57 & 32,50 & 32,47 & 28,83 \\
\hline Metro & 678 & 561 & 754 & 724 & 821 & 913 & 911 & 4,53 & 8,23 & 9,63 & 9,15 & 10,06 & 10,84 & 10,45 \\
\hline $\begin{array}{l}\text { All water } \\
\text { transport }\end{array}$ & 45 & 12 & 6 & 5 & 5 & 4 & 3 & 0,30 & 0,18 & 0,08 & 0,06 & 0,06 & 0,05 & 0,03 \\
\hline Nautical & 26 & 8 & 4 & 3 & 4 & 3 & 2 & 0,17 & 0,12 & 0,05 & 0,04 & 0,05 & 0,04 & 0,02 \\
\hline River & 19 & 4 & 2 & 2 & 1 & 1 & 1 & 0,13 & 0,06 & 0,03 & 0,03 & 0,01 & 0,01 & 0,01 \\
\hline Air Transport & 15 & 2 & 1 & 1 & 2 & 3 & 5 & 0,10 & 0,03 & 0,01 & 0,01 & 0,02 & 0,04 & 0,06 \\
\hline Total amount & 14977 & 6816 & 7826 & 7911 & 8164 & 8423 & 8718 & 100,00 & 100,00 & 100,00 & 100,00 & 100,00 & 100,00 & 100,00 \\
\hline
\end{tabular}

In 2000 , there were 7.826 billion passengers and 113.6 billion passenger-kilometers in Ukraine, this figure is growing every year and in 2019 reached 8.718 billion passengers and 148.4 billion passenger-kilometers. Land transport is dominant, compared with 1990, water and air passenger transport has almost disappeared. The share of railway transport in the market was $4.5 \%$ in 1990 and $6.4 \%$ in 2000, and in $20195.88 \%$. In 2017, the average travel distances by rail and air were respectively $103.8 \mathrm{~km}$ and $1700 \mathrm{~km}$ (Kichirok \& Onishchak, 2014).

The development of passenger traffic and passenger flow in Ukraine is presented in the Table 2 and in Figure 1.

Table 2. Development of passenger transportation in Ukraine from 1990 to 2019

\begin{tabular}{|l|c|c|c|c|c|c|c|}
\hline \multirow{2}{*}{ Vehicle } & \multicolumn{7}{|c|}{ Passengers: index 100 for 1990} \\
\cline { 2 - 9 } & 1990 & 1995 & 2000 & 2005 & 2010 & 2015 & 2019 \\
\hline All ground transportation & 100 & 46 & 52 & 53 & 58 & 52 & 52 \\
\hline Railway & 100 & 86 & 75 & 78 & 82 & 86 & 91 \\
\hline Motor transport & 100 & 42 & 31 & 32 & 35 & 37 & 43 \\
\hline Trams & 100 & 41 & 69 & 71 & 72 & 71 & 70 \\
\hline Trolleybuses & 100 & 42 & 80 & 82 & 85 & 82 & 80 \\
\hline
\end{tabular}


End of Table 2

\begin{tabular}{|l|c|c|c|c|c|c|c|}
\hline \multirow{2}{*}{ Vehicle } & \multicolumn{7}{|c|}{ Passengers: index 100 for 1990 } \\
\cline { 2 - 9 } & 1990 & 1995 & 2000 & 2005 & 2010 & 2015 & 2019 \\
\hline Metro & 100 & 82 & 111 & 115 & 117 & 121 & 125 \\
\hline All water transport & 100 & 26 & 13 & 14 & 13 & 12 & 10 \\
\hline Nautical & 100 & 29 & 14 & 16 & 14 & 13 & 11 \\
\hline River & 100 & 19 & 11 & 12 & 11 & 10 & 8 \\
\hline Air Transport & 100 & 13 & 8 & 9 & 8 & 6 & 5 \\
\hline Total amount & 100 & 46 & 52 & 54 & 57 & 59 & 64 \\
\hline
\end{tabular}

Compared with the data of 1990, until 1996 there was a tendency towards a decrease in passenger traffic on all modes of transport. Since 1996, the decrease in passenger flow continued on such modes of transport as air, sea, river and motor transport. Metro, trolleybuses, trams or rail vehicles are in the process of recovery. In 2000, the total volume of passenger traffic reached 154 million passengers, which was only a third of the volume of traffic in 1990.

The volume of rail traffic in Ukraine for the years 1990-2018 from authors study you can see the change in passenger traffic at short and long-distance distances (Figure 2) (Ugnenko et al., 2020).

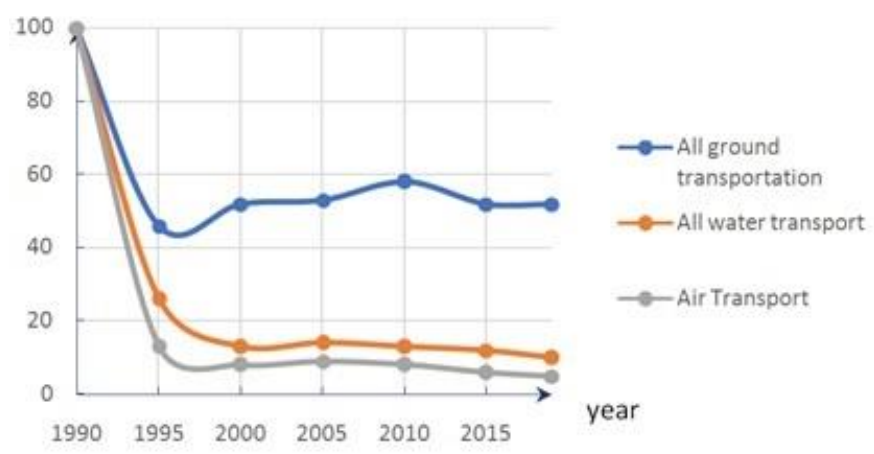

Figure 1. Change in passenger traffic in Ukraine

In 2010, the total long-distance rail traffic amounted to 91 million passengers and 34.9 billion pass-km, respectively $98 \%$ and $77 \%$ compared to 1990 . The share of local transportation in the total amount of intercity railway traffic is $29.5 \%$ in passenger units and $11.6 \%$ in pass-km, as shown in Figures 2 and 3.

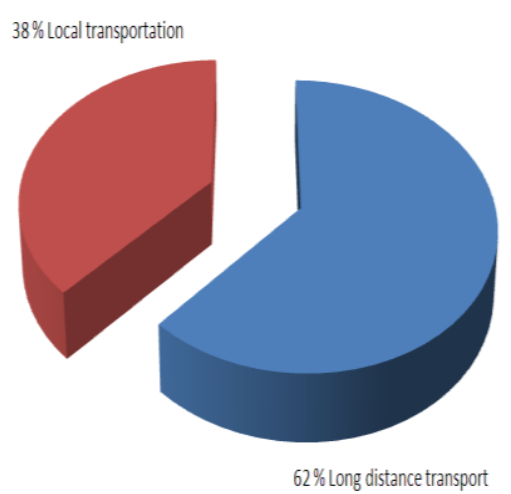

Figure 2. Volume of intercity rail transport in units of passengers (2019 year)

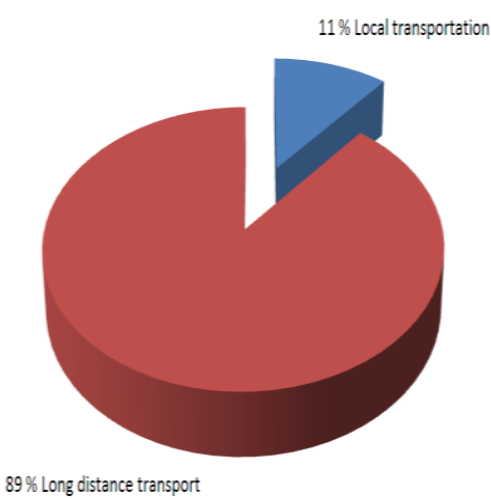

Figure 3. Volume of railway intercity traffic, passengerkilometers (2019 year)

According to the data obtained from the State Statistics Service of Ukraine, passenger traffic can be calculated based on known parameters (Kirpa, 2004; Kurhan, M. \& Kurhan, D., 2017). 
The demand for a high-speed line route can theoretically be calculated by the formula:

$$
\Pi_{a b}=k \frac{H_{A} \cdot H_{B}}{f\left(L_{m} \cdot T_{m}\right)},
$$

where: $\Pi_{a b}$ - volume of traffic between two terminal stations A and $\mathrm{B} ; H_{A}, H_{B}$ - population of two terminal stations A and B; $L_{m}$ - route length; $T_{m}$ - the duration of the trip by high-speed train on the route between stations A and B; $k, f$ - model coefficient and travel frequency.

By the formula (1), it is possible to determine not only the passenger turnover but also to find the optimal line plan to find the best option, which is used with a small interval of uncertainty.

According to this technique, we will carry out the calculation to determine the growth in the direction of KievLviv from 2020 to 2032. The results are shown in Figure 4.

One of the tasks of creating a high-speed railway network is to ensure the transportation of people between cities in comfortable fast trains on direct routes with a high frequency of movement (Pogrebnyak et al., 2019).

The basic principle for determining routes is to conduct direct routes between large cities with a minimum number of intermediate stops in cities of special significance.

Key high-speed rail services include:

- Designed, designed and built routes of a high-speed railway line;

- The duration of trips between cities;

- Frequency of movement on each route.

Due to the sharp reduction in travel time compared to the current one, the duration of high-speed rail travel will be very competitive.

In the future, it is necessary to carry out a detailed study of each direction, taking into account all the characteristics of the infrastructure, subsystems, rolling stock and operation (Kurgan et al., 2014).

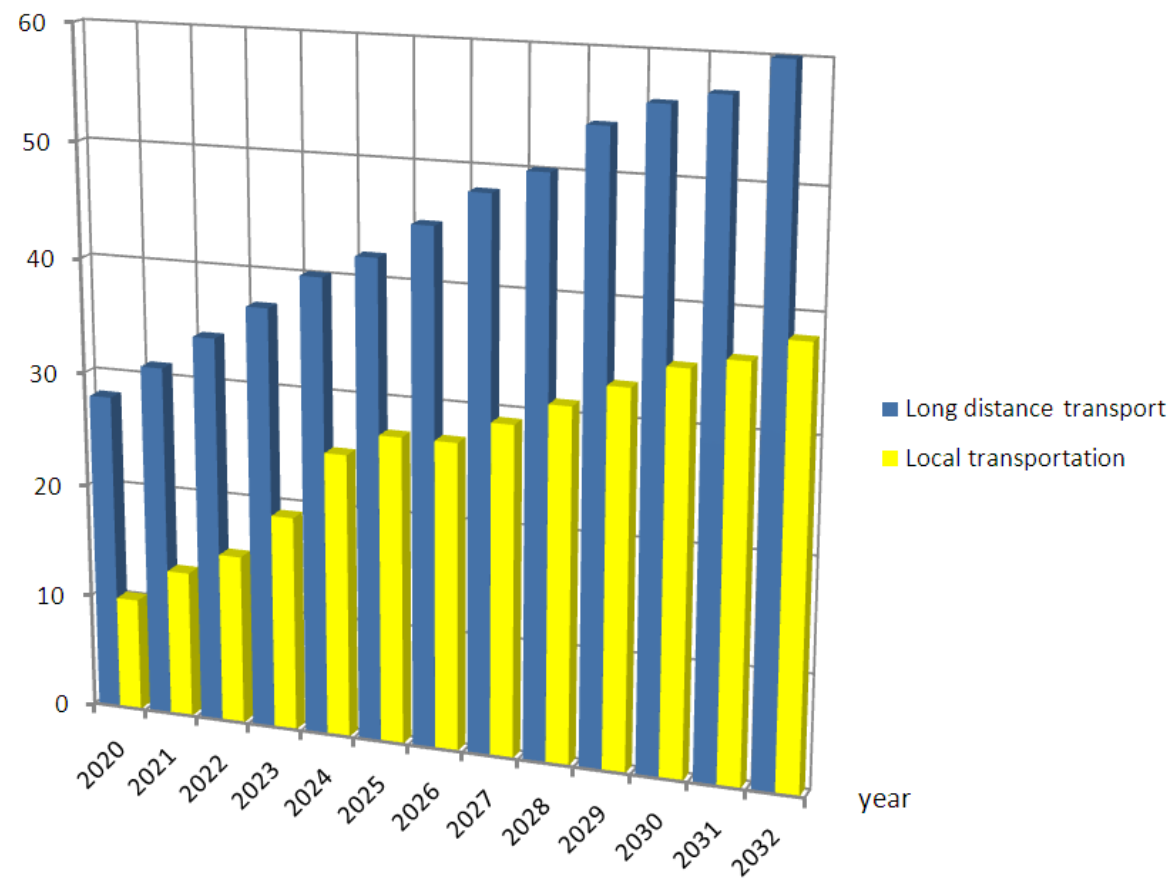

Figure 4. The volume of passenger traffic in the direction of Kiev-Lviv

From the point of view of commercial operation, the available experience shows that, as a rule, the speed of movement on high-speed lines is $250-300 \mathrm{~km} / \mathrm{h}$. However, tests were carried out on some lines to organize traffic at speeds of more than $300 \mathrm{~km} / \mathrm{h}$ (up to $320 \mathrm{~km} / \mathrm{h}$ ). It should be noted that the following factors limit this speed: economic (commercial issues or energy supply issues, etc.), technical (related to rolling stock or stationary equipment) or environmental protection factors (determining routes, noise, etc.)

It is necessary to take into account the fact that in the future the current situation will change for some routes and types of services. For the first time in Europe, traffic along a 60-kilometer stretch of the new TGV Mediterranean line is organized at a speed of $320 \mathrm{~km} / \mathrm{h}$. On the Madrid - Barcelona route with a length of $625 \mathrm{~km}$ and a trip duration of 2 hours 15 minutes -2 hours 30 minutes (direct average commercial speed is $250-278 \mathrm{~km} / \mathrm{h}$ ). In view of the speed limits 
introduced at the entrances to large cities, a speed of more than $300 \mathrm{~km} / \mathrm{h}$ on the line appears to be significant. The base level for this new railway line is $350 \mathrm{~km} / \mathrm{h}$. In the near future, this speed will become the basis for a network of high-speed railways in Europe (Connolly \& Forde, 2015).

The network of high-speed railways proposed for Ukraine will be implemented over 30-40 years, with the possible launch of the first project in 2020 or 2025 . In the study, the speed of $350 \mathrm{~km} / \mathrm{h}$ is taken as the base speed.

The design of high-speed lines should comply with the following general requirements aimed at satisfying the basic characteristics of the high-speed railway system that are presented in Table 3.

Our task is to present a basic concept of infrastructure and a summary of the basic requirements, including the most important conditions and functioning parameters, interacting with other planned tasks and systems.

The compatibility of the parameters of high-speed lines with the parameters of traditional lines is part of the operational requirements for the gradual introduction of a network of high-speed railways. Possible scenarios to achieve the required compatibility should cover all subsystems.

As a result of using the above-mentioned principles of line layout, some land plots need to be purchased to implement the project of high-speed lines in Ukraine. The appropriate location and number of these sections will be considered at the next stage of the study, since the corresponding territory is determined on the basis of numerous technical requirements, for example, the use of embankments or pits for the track, or the installation of substations near the lines.

Whatever the procedure for the alienation of lands in Ukraine, it must be emphasized that this important process at the stage of project implementation will require the implementation of all Ukrainian laws that govern these issues. Appropriate actions must be performed by the Project Customer (Fischer \& Nèmeth, 2018).

Table 3. The requirements of the main characteristics of the high-speed system

\begin{tabular}{|l|l|}
\hline \multicolumn{1}{|c|}{$\begin{array}{c}\text { Key Features of the High-Speed } \\
\text { Rail System }\end{array}$} & \multicolumn{1}{|c|}{ General requirements for laying lines } \\
\hline $\begin{array}{l}\text { Direct line between the centers of } \\
\text { big cities. }\end{array}$ & Using the existing infrastructure of the main stations of large cities \\
\hline $\begin{array}{l}\text { Connection with city/subur-ban and } \\
\text { other railway services at nodal } \\
\text { points. }\end{array}$ & $\begin{array}{l}\text { Use of existing equipment of long-distance trains for high-speed trains, if the project } \\
\text { does not allow, the shortest system of movement of passengers delivered by local or } \\
\text { regional modes of transport. }\end{array}$ \\
\hline Minimize the duration of the trip. & $\begin{array}{l}\text { Designing the most direct laying of lines between the main stations with the maximum } \\
\text { possible length of track sections with the parameters of a high-speed railway. } \\
\text { Design with the smallest distance between the platform and standard arrangement of } \\
\text { train doors. }\end{array}$ \\
\hline Maximize infrastructure costs. & $\begin{array}{l}\text { Design of all infrastructure subsystems with parameters that are standard for high- } \\
\text { speed lines, which eliminates the use of ground road and rail crossings, except for } \\
\text { high-speed overpasses and switches at nodal points. Maximum reduction in line length } \\
\text { due to the use of standard operational characteristics of high-speed trains, as well as } \\
\text { optimizing maximum allowable tilt angles and curves. }\end{array}$ \\
\hline Maximize operating costs. & $\begin{array}{l}\text { Design of a depot for maintenance of infrastructure and rolling stock, taking into } \\
\text { account the location of routes. }\end{array}$ \\
\hline $\begin{array}{l}\text { Maximize the cost of project } \\
\text { implementation stages. }\end{array}$ & $\begin{array}{l}\text { Design interoperability between high-speed and existing lines, so that high-speed trains } \\
\text { can run along existing lines. }\end{array}$ \\
\hline
\end{tabular}

To illustrate the problems that may arise during the alienation of land, we can outline the main provisions of land valuation in Ukraine. Comparison Table 4 presents the main differences between the two types of assessment.

Table 4. The main provisions of land valuation in Ukraine

\begin{tabular}{|l|l|}
\hline \multicolumn{1}{|c|}{ Cashvaluation } & \multicolumn{1}{c|}{ Expert Assessment / Costing } \\
\hline It is normative in nature. & Has a market character. \\
\hline $\begin{array}{l}\text { Considers a plot of land separately } \\
\text { from real estate located on it. }\end{array}$ & Examines a plot of land together with real estate located on it. \\
\hline $\begin{array}{l}\text { Examines improvements made on a } \\
\text { plot of land, just beyond. }\end{array}$ & Examines improvements made on and off the land. \\
\hline Focused on typical features. & Focuses on certain characteristics, including specific transaction conditions. \\
\hline Deals with potential rental income. & Deals with real rental income. \\
\hline
\end{tabular}


End of Table 4

\begin{tabular}{|l|l|}
\hline \multicolumn{1}{|c|}{ Cashvaluation } & \multicolumn{1}{c|}{ Expert Assessment / Costing } \\
\hline $\begin{array}{l}\text { Does not take into account market } \\
\text { conditions and current economic } \\
\text { conditions. }\end{array}$ & Takes into account the state of the market and the current economic situation. \\
\hline $\begin{array}{l}\text { The cost is determined based on the } \\
\text { area of the land. }\end{array}$ & The cost is determined based on profitable activities on the site. \\
\hline
\end{tabular}

Monetary valuation is used when evaluating land for the conclusion of civil contracts. Also, monetary valuation of land is used in the calculation of taxes. Expert evaluation is used much less frequently. This type of assessment is used for the sale of land with dormant objects or construction in progress, and is also the starting price at the auction (Potapov et al., 2018).

\section{Conclusions}

The transformation of basic requirements into technical solutions, as well as a reliable and cost-effective infrastructure system should be carried out by a more detailed study for each project.

The high-speed rail system is divided into subsystems with numerous connecting links between them:

- Subsystem of control and management;

- Track subsystem;

- Energy supply subsystem;

- A subsystem of rolling stock.

The characteristics of the high-speed railway system are due to the following:

- Functions necessary for the safe implementation of railway traffic and for operation, both in normal and in worsened conditions;

- The interaction of the composition, train equipment, and communication equipment of the train with the railway line, etc;

- The level of operation necessary to meet basic requirements.

The most important requirements for each of the subsystems are:

- Safety: each new project should include the necessary measures so that the level of risk of accidents for each subsystem does not exceed the objective level necessary for maintenance. To this end, specific and very stringent requirements have been identified. Acceptable standards for safe operation mu st be established;

- Reliability, efficiency and maintenance: the general requirements for the design of each subsystem should provide a controlled level of risk, the service life and wear of the component parts. Quality of service should ensure safety;

- Protection of the health of passengers and staff: precautions must be taken to ensure that the materials used and the design of each subsystem do not pose a threat to the health of people with access to them;

- Environmental protection: each subsystem should not contain substances that, under normal use, pollute the environment, for example, by the emission of fumes or gases, the creation of electromagnetic interference, etc;

- Technical compatibility: possible compatibility with the present and traditional network that is used in Ukraine should be preserved in order to facilitate travel and not interfere with operation.

\section{Author contributions}

Anna Shevchenko and Natalya Bugaec conceived the study and were responsible for the design and development of the data analysis. Nadiia Murygina and Yevhen Korostelov were responsible for data collection and analysis. Anna Shevchenko and Gintas Viselga were responsible for data interpretation. Anna Shevchenko wrote the first draft of the article.

\section{References}

Connolly, D., \& Forde, M. (2015). Use of conventional site investigation parameters to calculate critical velocity of trains from Rayleigh waves. Transportation Research Record: Journal of the Transportation Research Board, 2476(1), 32-36. https://doi.org/10.3141/2476-05

Fischer, S., \& Nèmeth, A. (2018). Special laboratory testing method for evaluation particle breakage of railway ballast material. Science and Transport Progress, 2(74), 87-102. https://doi.org/10.15802/stp2018/130854 
Kichirok, I., \& Onishchak, R. (2014). Creating digital maps for the use of auto navigation. Bulletin of Geodesy and Cartography, 2(89), 49-51.

Kirpa, G. (2004). Integration of Ukraine's railway transport into the European transport system. Dnipropetrovsk National University of Railway Transport. Dnipro. Ukraine.

Kurgan, M., Baydak, S., \& Khmelevska, N. (2014). Prerequisites for the introduction of accelerated train movement in the direction of Kuma - Dnipropetrovsk. Ukrainian Railways, 10(16), 51-64.

Kurhan, M., \& Kurhan, D. (2017). Science and transport progress. Bulletin of Dnipropetrovsk National University of Railway Transport, 6(72), 40-48. https://doi.org/10.15802/stp2017/118380

Nikitin, A. (2018). Theory and methods of geodetic support road transport infrastructure (Thesis for the degree of doctor of technical sciences). Novosibirsk: Siberian State University of Geosystems and Technologies. 230 p.

Pogrebnyak, V., Shevchenko, A., \& Matvienko, O. (2019). Accuracy of terrain survey and processing of received data on international transport corridors and high-speed highways. Metrology and Instrumentation Scientific and Production Journal, 75(1), 21-24. https://doi.org/10.33955/2307-2180(1)2019.21-24

Potapov, D., Panchenko, S., Leibuk, Y., Tuley, Y., \& Plis, P. (2018). Effect of joint and isolated irregularities of the track on the wear of rails in curves. In MATEC Web of Conferences: Transbud-2018, 230. https://doi.org/10.1051/matecconf/201823001012

Shevchenko, A. (2018). High-speed movement on Ukraian railways, steps of implementation. In Materials of $80^{\text {th }}$ International Scientific and Technical Conference, 177, Kharkov, Ukraine, 112-113.

Shevchenko, A., Matviienko, O., Lyuty, V., Manuylenko, V., \& Murygina, N. (2019). Digital models and the effect of error when shooting terrain for high-speed traffic. In IOP Conference Series: Materials Science and Engineering, 708, 012028. https://doi.org/10.1088/1757-899X/708/1/012028

Shevchenko, A., Matviienko, O., Lyuty, V., Manuylenko, V., \& Pavliuchenkov, M. (2018). Ways of introduction of the high-speed movement of passenger trains in Ukraine. In MATEC Web of Conferences: Transbud-2018, 230, 01007. https://doi.org/10.1051/matecconf/201823001007

Sysyn, M., Gerber, U., Kovalchuk, V., \& Nabochenko, O. (2018). The complex phenomenological model for prediction of inhomogeneous deformations of railway ballast layer after tamping works. Archives of Transport, 47(3), 91-107. https://doi.org/10.5604/01.3001.0012.6512

Ugnenko, E., Shevchenko, A., Matviienko, O., Maliavin, A., Viselga, G., \& Turla, V. (2020). Analysis of existing train lines and international railway transport corridors of Ukraine. In TRANSBALTICA XI: Transportation science and technology: Proceedings of the International Conference TRANSBALTICA, 2-3 May 2019, Vilnius, Lithuania, 622-632. https://doi.org/10.1007/978-3-030-38666-5_65 